\title{
The Effects of Spinopelvic Parameters Such As Lumbar Lordosis and Sacral Slope Angles in the Development of Lumbar Disc Degeneration
}

\author{
(D) Atilla KIRCELLI'1 ${ }^{1}$, id İlker ÇÖVEN², id Pelin ŞEN³, id Osman ORMAN4
}

1Başkent University Faculty of Medicine, Department of Neurosurgery, İstanbul, Turkey

${ }^{2}$ Konya Training and Research Hospital, Clinic of Neurosurgery, Konya, Turkey

${ }^{3}$ Bezmialem Vakıf University Faculty of Medicine, Department of Anesthesiology and Reanimation, İstanbul, Turkey

${ }^{4}$ Private Reyap Hospital, Clinic of Orthopedics, İstanbul, Turkey

\section{ABSTRACT}

Objective: Spinopelvic parameters were identified and the association between sagittal spinopelvic alignment and lumbar disc diseases have been reported in several studies. The purpose of this study was to evaluate the spinopelvic parameters such as lumbar lordosis (LL) and sacral slope (SS) in normal healthy lumbar spine versus degenerative disc disease group.

Methods: We retrospectively identified 140 patients suffered from back pain with/without radiculopathy between 2016-2017 in this study. Of these 70 patients had normal disc morphology and they constituted called control group, and the other 70 patients had lumbar degenerative disc disease and they constituted called disease patient group. All patients' LL, and SS angles were measured on T2 weighted sagittal magnetic resonance imaging and degenerated disc levels were noted. We also recorded LL-SS ratio which was calculated by dividing of LL by SS value in both groups. We compared these parameters between two groups.

Results: In disease patient group there was a positive correlation $(r=0.947, \mathrm{p}<0.0001)$ between the LL and SS angles. The mean LL was $45.14 \pm 11.01$ and the mean SS angle was 35.91 \pm 7.67 degrees and there was weak negative correlation between degenerated disc level and SS angle $(r=-0.243, p=0.042)$. LL-SS ratio was $1.25 \pm 0.1$. In control group, there was a positive correlation $(r=0.927, p<0.0001)$ between the LL and SS angles. The mean LL was $49.46 \pm 9.07$ and the mean SS was $38.45 \pm 6.91$ degrees. LL-SS ratio was $1.28 \pm 0.93$. There were significant differences in LL, SS and LL-SS ratio between groups ( $\mathrm{p}=0.013, \mathrm{p}=0.041$, and $\mathrm{p}=0.025$, respectively).

Conclusion: LL, SS angles and LL-SS ratio which are easily measured at in neurosurgery, orthopaedics and physical therapy practice, may be the predictor of disc degeneration.

Keywords: Spinopelvic parameters, lumbar lordosis, sacral slope, disc degeneration

\section{Introduction}

The spinal balance is provided by the placement of spine with proper lordosis on pelvis. For this reason, a relationship is tried to be established between the relation of the pelvis with the spine and diseases of the spine. As a result of the studies, spinopelvic parameters were defined by Duval-Beaupere et al. (1-3). Many studies have identified the relationship between degenerative spondylolisthesis and impaired spinopelvic balance. The relationship between sagittal spinopelvic balance and lumbar disc diseases (LDD) has been demonstrated by several studies in recent years (4-7).
Address for Correspondence: Atilla KIRCELLi, Başkent University Faculty of Medicine, Department of Neurosurgery, istanbul, Turkey

E-mail: atillakircelli@gmail.com ORCID ID: orcid.org/0000-0003-2109-1274

Cite this article as: Kırcelli A, Çöven $\mathrm{I}$, Şen P, Orman O. The Effects of Spinopelvic Parameters Such As Lumbar Lordosis and Sacral Slope Angles in the Development of Lumbar Disc Degeneration. Bezmialem Science 2019;7(1):23-7.

${ }^{\circ}$ Copyright 2019 by the Bezmiâlem Vakıf University

Bezmiâlem Science published by Galenos Publishing House.
Received: 13.09 .2017

Accepted: 08.01.2018 
Some sagittal spinopelvic parameters were lumbar lordosis (LL) and sacral slope (SS). Pelvic incidence (PI) reaches a permanent fixed value with the completion of growth; it is not affected by position, posture and degenerative diseases of spine and pelvis; it is a fixed morphological parameter $(4,8,9)$. PI consists of the sum of pelvic tilt (PT) and SS and these two values may vary. There is a correct proportional relationship between SS and LL (2).

Increased angle of PI was determined as a predisposing factor in the pathogenesis and development of degenerative spondylolisthesis, resulting in increased PI, increased SS, and increased LL $(4,8,9)$. Increased LL values have been shown in some studies to increase the risk of spondylolisthesis by increasing shear stress in lumbosacral junction. Some authors describe characteristic spinopelvic features in patients with LDD (4-6). Endo et al. (5) and Rajnics et al. (6) and observed decreased SS, decreased LL and anterior-shifted sagittal vertical axis (SVA) in patients with LDD. Although Barrey et al. (4) opposed that asymptomatic individuals might have abnormal spinopelvic angles, Yang et al. (7) showed disc degeneration in magnetic resonance imaging of asymptomatic individuals with abnormal spinopelvic values and revealed the relationship between spinopelvic values and LDD.

The aim of this study was to compare the LL and SS angles, which can be easily calculated from the MRI images between patient and control groups and to find out the relationship between LL and SS angles and the disk levels of degenerative disc disease.

\section{Methods}

Seventy consecutive patients with single or two levels disc degeneration or disc hernias in lumbar MRI, and 70 consecutive patients without disc degeneration or disc hernias, whose disc morphology was completely normal, were retrospectively selected from all the patients who were admitted to our clinic with back and/or leg pain between 2016-2017 for the study. This study was approved by the Başkent University Institutional Review Board (number: KA15/279) and written informed consent form was obtained from each patient. Patients with normal disc morphology were referred as control group, and patients with disk degeneration were referred as the patient group. Patients with 3 or more levels of disc degeneration, spondylosis, spondylolisthesis, spinal stenosis, scoliosis, vertebral fractures, infective processes such as osteomyelitis-discitis, spondyloarthropathies and previously operated patients (patients with discectomy or spinal fusion surgery) were excluded from the study.

The same 1.5 T MRI technique in which the signals are maximized using spine coil (Signa Excite, GE Medical Systems, Milwaukee, WI, USA) was used in all the patients in our radiology department. Lombar MRIs of both groups were investigated, and LL and SS angels were measured by the Clear Canvas program. Although LL is the lordotic angle of the lumbar vertebrae, it is the angle between the parallel line from the L1 vertebra upper end plate and the line tangled to the sacral vertebrae final plate in the T2 sagittal plane of the lumbar MRI (Figure 1A). The angle of the sacral curve is the angle between the parallel line passing through the upper plate of sacrum and the horizontal line in the same MRI cross section (Figure 1B). A radiologist calculated these angles along with the impaired disc levels and recorded them in the patients' medical recordings. Age, gender, and other data were recorded from the patiens' recordings.

A strong correlation was shown in many studies between LL and SS as indicated in the medical literature. In our study, when we divide the LL angle to the SS angle, the resulting value was calculated and recorded in both groups under the name of the LL-SS ratio.

\section{Statistical Analysis}

Correlation between age, gender, degenerated disc levels, LL, SS, LL-SS ratio in the groups was measured by the Pearson correlation test. The mean values of age, LL, SS and LL-SS ratio in both groups were compared by t-test. Descriptive statistics were expressed as mean and standard deviation for variables with normal distribution. P value below 0.05 was accepted as statistically significant. All statistical tests were performed with SPSS software for Windows (version 21.0; IBM, Armonk, NY, USA).

\section{Results}

There were 70 individuals in the control group consisting of 22 males $(31.4 \%)$ and 48 females $(68.6 \%)$ and the mean age was $38.17 \pm 13.21$ years. There were 70 patients with lombar disc degeneration in the patient group consisting of 35 males $(50 \%)$ and 35 females $(50 \%)$ and the mean age was $45.58 \pm 15.62$ years. There was statistically significant difference between the groups in terms of age $(\mathrm{p}=0.003)$. Impaired disc levels and demographic features of the patients were given in Table 1 .

The mean LL value was $45.14 \pm 11.01$ degrees and the mean SS value was 35.91 \pm 7.67 degrees in the patient group. There was a weak correlation between age and LL and SS $(r=0.25, \mathrm{p}=0.037$ and $\mathrm{r}=0.245, \mathrm{p}=0.041$, respectively). There was a proportional strong correlation between LL and SS ( $\mathrm{r}=0.947, \mathrm{p}<0.0001)$. The more caudal disc degeneration levels, the smaller SS angles; however there was a still weak correlation ( $\mathrm{r}=0.243, \mathrm{p}=0.042$, respectively). The mean LL-SS ration was $1.25 \pm 0.1$ in the patient group.

The mean LL value was $49.46 \pm 9.07$ degrees and the mean SS value was $38.45 \pm 6.91$ degrees in the control group. There
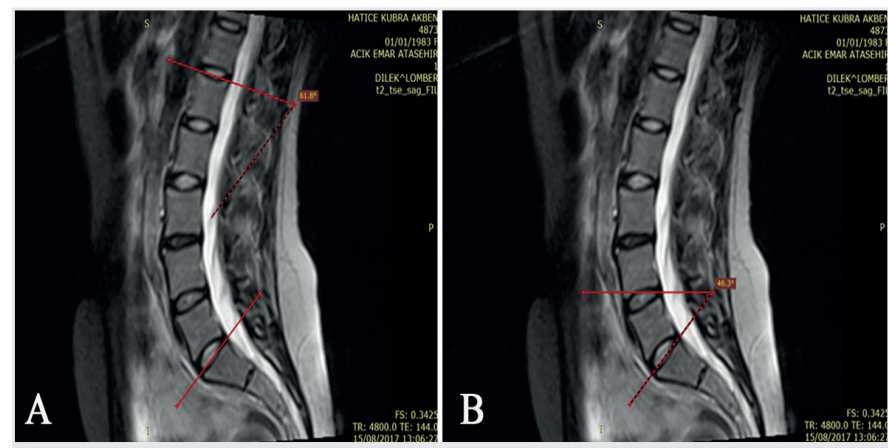

Figure 1. T2-weighted sagittal lumbar magnetic resonance imaging shows lumbar lordosis angle $(A)$ and sacral slope angle (B) 
Table 1. Demographic features

\begin{tabular}{|l|l|l|l|}
\hline & \multicolumn{1}{l}{ Control group } & Patient group & p values \\
\hline Age (years \pm SD) & $38.17 \pm 13.21$ & $45.58 \pm 15.16$ & 0.003 \\
\hline Gender $(n, \%)$ & & & 0.025 \\
\hline Male & $22(31.4 \%)$ & $35(50 \%)$ & - \\
\hline Female & $48(68.6 \%)$ & $35(50 \%)$ & - \\
\hline Impaired disc levels (n, \%) & & \\
\hline L2-3 & - & $3(4.3 \%)$ & - \\
\hline L3-4 & - & $7(10 \%)$ & - \\
\hline L3-4 and L4-5 & - & $3(4.3 \%)$ & - \\
\hline L4-5 & - & $23(32.9 \%)$ & - \\
\hline L4-5 and L5-S1 & - & $11(15.7 \%)$ & - \\
\hline L5-S1 & - & $23(32.9 \%)$ & - \\
\hline SD: standard deviation & & & \\
\hline
\end{tabular}

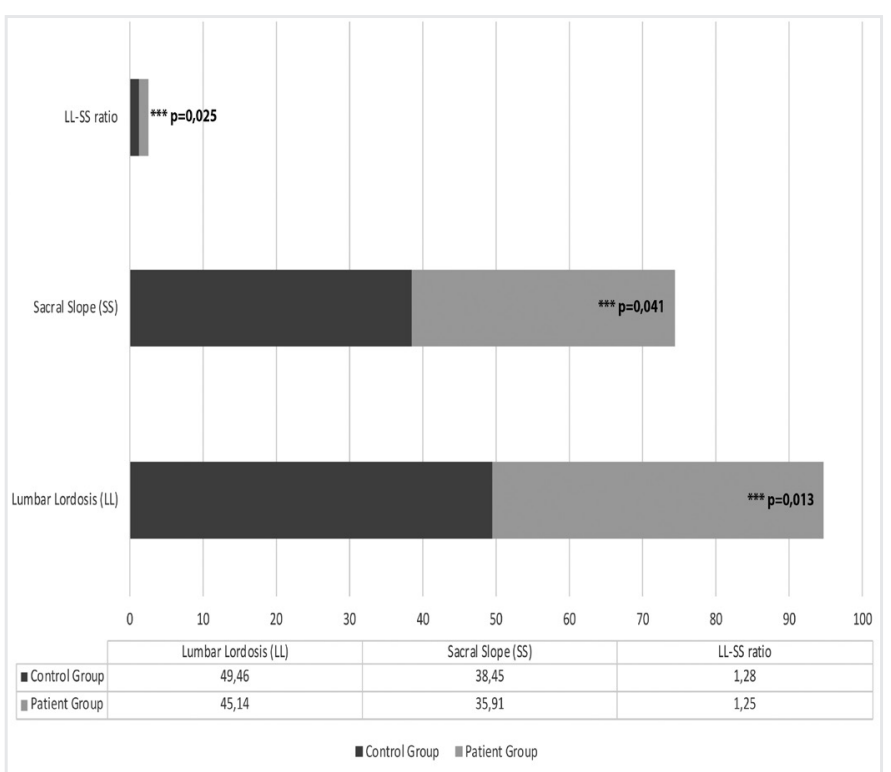

Figure 2. Comparison of spinopelvic parameters in control and patient groups

was a strong correlation between LL and SS angles $(r=0.927$, $\mathrm{p}<0.0001)$. The mean LL-SS ration was $1.28 \pm 0.93$ in the control group.

There were statistically significant differences between the groups in terms of the mean LL and SS angles and LL-SS ratios ( $\mathrm{p}=0.013, \mathrm{p}=0.041$ and $\mathrm{p}=0.025$, respectively) (Figure 2).

\section{Discussion}

The prevalence of back pain in adults is between $60 \%$ and $90 \%$. Discogenic pain is one of the most important causes of low back pain and it is thought that LL and changes in sacral parameters are very important causes of discogenic pain. In many studies on lumbosacral morphology, the relation of back pain with LL and SS angles in isthmic spondylolisthesis has been studied, but this relation in more frequent pathologies such as intervertebral disc degeneration or disc hernias have been less studied (10).
The direct relationship between LL and SS angle has been shown in many studies (11-13). Diseases affecting the lumbar region or sacropelvic junction disrupt the sagittal balance and lead to compensatory changes such as an increase or decrease in thoracic kyphosis. The increase in physiological kyphosis in the thoracic region results in a shift of the sagittal balance line to the front; the decrease in physiological kyphosis in the thoracic region results in a shift of the sagittal balance line to the back. The increase in physiological kyphosis in the thoracic region results in a shift of the sagittal balance line to the front; the decrease in sagittal balance line to the back of the way to change. Anatomical and positional parameters used in the analysis of the sacropelvic compound are available. The main positional parameters are lumbosacral, L5 incidence, PT and SS angles. Although these parameters are used in the evaluation of different regions, they are constantly interrelated. A change in a region or in a parameter results in compansatuary response in other parameters to restore sagittal balance (14).

It is known that pelvic morphology affects sagittal spinal geometry in particular, LL angle (14). The effect of pelvic morphology on spinal balance in the progression and treatment of spinal deformities should be well understood. PI is the sum of SS and PT. It is accepted that spinopelvic balance changes are compensated by changes in PT and SS angle to keep PI angle stable. Theoretically, PI angle is constant. Mac-Thiong et al. (15) investigated the relationship between toracic kyphosis, LL, PI, SS and PT in children adolescents in 2005. They found mild relation between toracic kyphosis and LL and strong relation between SS and LL. A direct relation between toracic kyphosis and PT was not established. Gottfried et al. (16) showed decrease in LL and increase in PI and PT in patients with iatrogenic flatback. This compensatory mechanism prevents the increase of kyphosis. With these parameters, LL-SS ratio has not been previously reported in the literature. The mean constant value of 1.3 calculated in the control group with normal disc morphology was low and suggested that disc degeneration might develop. This value was lower in the patient group and there was a statistically significant difference between groups in terms of LL-SS ratio.

In patients with degenerative disc disease and disc hernias, there is a more flat spine, characterized by decreased thoracic kyphosis and decreased LL. In these individuals, PI appears to be lower than normal population. Rose et al. (17) suggested that the sum of thoracic kyphosis, LL and pelvic indices should be less than 45 degrees for a healthy spinopelvic balance (18). Yang et al. (7) observed that PI was lower in patients with lumbar degenerative disc, and that the angles of the SS and PT were decreased, and finally, that flatter LL and thoracic kyphosis developed. A flattened spine and more vertically positioned sacrum increases the compressive forces created by gravity and accelerates disc degeneration $(6,19-21)$. On the other hand, the absorption of the shaking loads formed by these vertical forces will decrease and result in the formation of disc hernias. The decrease in LL will shift the SVA line to the fore; and will activate the hip extensors resulting in pelvic backtilts $(2,4,5,9,22)$. It is suggested that lumbar discectomy improves the LL and that SVA approaches to normal limits and thus pain is reduced (5). 
We believe that the changes in disc morphology have an effect on many lumbosacropelvic angles and biomechanics of the spinal structure together. Therefore, lumbosacropelvic morphology in male and female patients may be related with the quality of life after lumbar disc herniation surgery.

In the present study, it was shown that LL and SS angles were predisposing factors in the development of degenerative disc disease. In many studies it was shown that there was a relationship between LL and SS $(23,24)$. However, in this study, there was statistically significant difference between the patient group and the control group with normal spinal morphology in terms of LL and SS means. It can also be concluded that the LL and SS angles may be predisposing factors for the development of disc degeneration. However, the patients in the control group were not followed up for many years and it is not known whether controls will develop or not develop disc degeneration over time.

\section{Study Limitations}

Retrospective design based on the medical recordings of the patients, lack of follow-up results of the control group in the study for many years and lack of a prospective or randomized design were the limitations of the study. In addition, patients in both groups did not exhibit similar characteristics in terms of age, gender, occupation and environmental factors, which could be a limitation in determining the development of disc degeneration. The existence of a control group and large number of patients were the strong sides of this study. However, fallibility of these results can be reduced by randomised, controlled and prospective studies.

\section{Conclusion}

The value of LL and SS angles and LL-SS ratio, which can be easily measured in neurosurgery, orthopedics or physical therapy practice, in predicting the development of disc degeneration should not be underestimated.

\section{Ethics}

Ethics Committee Approval: This study was approved by the Başkent University Institutional Review Board (number: KA15/279).

Informed Consent: Written informed consent form was obtained from each patient.

Peer-review: Externally peer-reviewed.

\section{Authorship Contributions}

Surgical and Medical Practices: A.K., İ.Ç., O.O., Concept: A.K., O.O., Design: İ.Ç., O.O., Data Collection or Processing: A.K., P.Ş., Analysis or Interpretation: A.K., O.O., P.Ş., Literature Search: İ.Ç., P.Ş., Writing: A.K., O.O., İ.Ç.

Conflict of Interest: No conflict of interest was declared by the authors.

Financial Disclosure: The authors declared that this study received no financial support.

\section{References}

1. Duval-Beaupere G, Schmidt C, Cosson P. A Barycentremetric study of the sagittal shape of spine and pelvis: the conditions required for an economic standing position. Ann Biomed Eng 1992;2:451-62.

2. Legaye J, Duval-Beaupere G, Hecquet J, Marty C. Pelvic incidence: a fundamental pelvic parameter for three-dimensional regulation of spinal sagittal curves. Eur Spine 1998;7:99-103.

3. During J, Goudfrooij H, Keessen W, Beeker TW, Crowe A. Toward standards for posture. Postural characteristics of the lower back system in normal and pathologic conditions. Spine (Phila Pa 1976) 1985;10:83-7.

4. Barrey C, Jund J, Noseda O, Roussouly P. Sagittal balance of the pelvis-spine complex and lumbar degenerative diseases. A comparative study about 85 cases. Eur Spine 2007;16:1459-67.

5. Endo K, Suzuki H, Tanaka H, Kang Y, Yamamoto K. Sagittal spinal alignment in patients with lumbar disc herniation. Eur Spine J 2010;19:435-8.

6. Rajnics P, Templier A, Skalli W, Lavaste F, Illes T. The importance of spinopelvic parameters in patients with lumbar disc lesions. Int Orthop 2002;26:104-8.

7. Yang X, Kong Q, Song Y, Liu L, Zeng J, Xing R. The characteristics of spinopelvic sagittal alignment in patients with lumbar disc degenerative diseases. Eur Spine J 2014;23:569-75.

8. Aono K, Kobayashi T, Jimbo S, Atsuta Y, Matsuno T. Radiographic analysis of newly developed degenerative spondylolisthesis in a mean twelve-year prospective study. Spine (Phila Pa 1976) 2010;35:88791.

9. Barrey C, Jund J, Perrin G, Roussouly P. Spinopelvic alignment of patients with degenerative spondylolisthesis. Neurosurgery 2007;61:981-6.

10. Arts MP, Peul WC, Koes BW, Thomeer RT; Leiden-The Hague Spine Intervention Prognostic Study (SIPS) Group. Management of sciatica due to lumbar disc herniation in the Netherlands: a survey among spine surgeons. J Neurosurg Spine 2008;9:32-9.

11. Stagnara P, De Mauroy JC, Dran G, Gonon GP, Costanzo G, Dimnet $\mathrm{J}$, et al. Reciprocal angulation of vertebral bodies in a sagittal plane: approach to references for the evaluation of kyphosis and lordosis. Spine (Phila Pa) 1982;7:335-42.

12. Vedantam R, Lenke LG, Bridwell KH, Linville DL, Blanke K. The effect of variation in arm position on sagittal spinal alignment. Spine (Phila Pa 1976) 2000;25:2204-9.

13. Vedantam R, Lenke LG, Keeney JA, Bridwell KH. Comparison of standing sagittal spinal alignment in asymptomatic adolescents and adults. Spine (Phila Pa 1976) 1998;23:211-5.

14. Edmondston SJ, Singer KP. Thoracic spine: anatomical and biomechanical considerations for manual therapy. Manual Ther 1997;2:132-43.

15. Mac-Thiong JM, Labelle H, Charlebois M, Huot MP, de Guise JA. Sagittal plane analysis of the spine and pelvis in adolescent idiopathic scoliosis according to the coronal curve type. Spine (Phila Pa 1976) 2003;28:1404-9. 
16. Gottfried ON, Daubs MD, Patel AA, Dailey AT, Brodke DS. Spinopelvic parameters in postfusion flatback deformity patients. Spine J 2009;9:639-47.

17. Rose PS, Bridwell KH, Lenke LG, Cronen GA, Mulconrey DS, Buchowski JM, et al. Role of pelvic incidence, thoracic kyphosis, and patient factors on sagittal plane correction following pedicle subtraction osteotomy. Spine (Phila Pa 1976) 2009;34:785-91.

18. Cheng I. Point of view: spinopelvic parameters in postfusion flatback deformity patients. Spine J 2009;9:672-3.

19. Vialle R, Levassor N, Rillardon L, Templier A, Skalli W, Guigui P. Radiographic analysis of the sagittal alignment and balance of the spine in asymptomatic subjects. J Bone Joint Surg Am 2005;87: 260-7.

20. Vaz G, Roussouly P, Berthonnaud E, Dimnet J. Sagittal morphology and equilibrium of pelvis and spine. Eur Spine J. 2002;11:80-7.
21. Roussouly P, Gollogly S, Berthonnaud E, Dimnet J. Classification of the normal variation in the sagittal alignment of the human lumbar spine and pelvis in the standing position. Spine (Phila Pa 1976). 2005;30:346-53

22. Barrey C, Roussouly P, Perrin G, Le Huec JC. Sagittal balance disorders in severe degenerative spine. Can we identify the compensatory mechanisms? Eur Spine J 2011;20(Suppl 5):626-33.

23. Zdeblick TA. The treatment of degenerative lumbar disorders. A critical review of the literature. Spine (Phila Pa 1976). 1995;20(24 Suppl):126-37.

24. Taylor VM, Deyo RA, Cherkin DC, Kreuter W. Low back pain hospitalization. Recent United States trends and regional variations. Spine (Phila Pa 1976) 1994;19:1207-12. 